$\mathrm{Oz}$

$1-1-1990$

\title{
The Architecture We Remember: The Real and the Mediated
}

Lisa R. Findley

Follow this and additional works at: https://newprairiepress.org/oz

Part of the Architecture Commons

(c) $19 \odot$

This work is licensed under a Creative Commons Attribution-Noncommercial-No Derivative Works 4.0 License.

\section{Recommended Citation}

Findley, Lisa R. (1990) "The Architecture We Remember: The Real and the Mediated," Oz: Vol. 12.

https://doi.org/10.4148/2378-5853.1198

This Article is brought to you for free and open access by New Prairie Press. It has been accepted for inclusion in Oz by an authorized administrator of New Prairie Press. For more information, please contact cads@k-state.edu. 


\title{
The Architecture We Remember: The Real and the Mediated
}

\author{
Lisa R. Findley
}

I.

The scenario has been played out with slight variations in architecture schools everywhere. It is the end of the term. A distinguished panel of critics has been assembled to review the work of the design studios. A student from an undergraduate studio presents a project that has a facade with randomly placed windows of varying size and proportion. The facade, the student says, is "like Ronchamps." The critics stretch their imaginations to Le Corbusier's powerful and poetic treatment of the thick south wall of Notre Dame du Haut. The student's version is weak and pathetic. The critics move in for the kill ...

II.

The focus of this paper is not the success of the student's perhaps facile borrowing, nor the vehemence critics display at the student's awkward attempt, but rather how it is that the student understands the source building. How is it that the student experienced Notre Dame du Haute and how did that experience affect the translation into his own work? In a larger sense, how do any of us understand the architecture and experiences that comprise our memories? How do we draw upon them when we design?

We are all familiar with the tendency in architecture to use existing buildings as references, precedents, and typological touchstones in design. Such borrowing is 36 used by practioners and students alike. It is a common and acceptable practice taught in architecture schools, and is reinforced by the profession. It is seen by most as a kind of compliment to the architecture: the referent building is serving as an inspiration. The building has, in some way, inspired with a strength, or poetry, or competence, or solution to a particular problem, or imagibility. It is in this way that architecture builds upon itself, rewarding both invention and convention.

We learn early in our educations that it is in some way useful to have in our image banks a store of admired buildings. If we have particularly clear instructors, we may even understand that one of the values of this is to have a sort of catalog of how certain recurring problems in architecture have been solved by masterful architects. We might even begin to create in our minds an informal typology of these solutions as a ready resource for problems we may encounter in design. We all (students and practioners alike) make these image banks by voraciously commiting to memory images of the admired buildings from photographs and drawing, from library books, from periodicals, and from slides in architectural history courses and public lectures on architecture.

An argument can be made that not all the sources that influence memory generate the same quality of images, ideas, and understandings to be drawn upon in architecture. When we use these memories, we add to them, adapt them, and translate them into a design reality. The com-

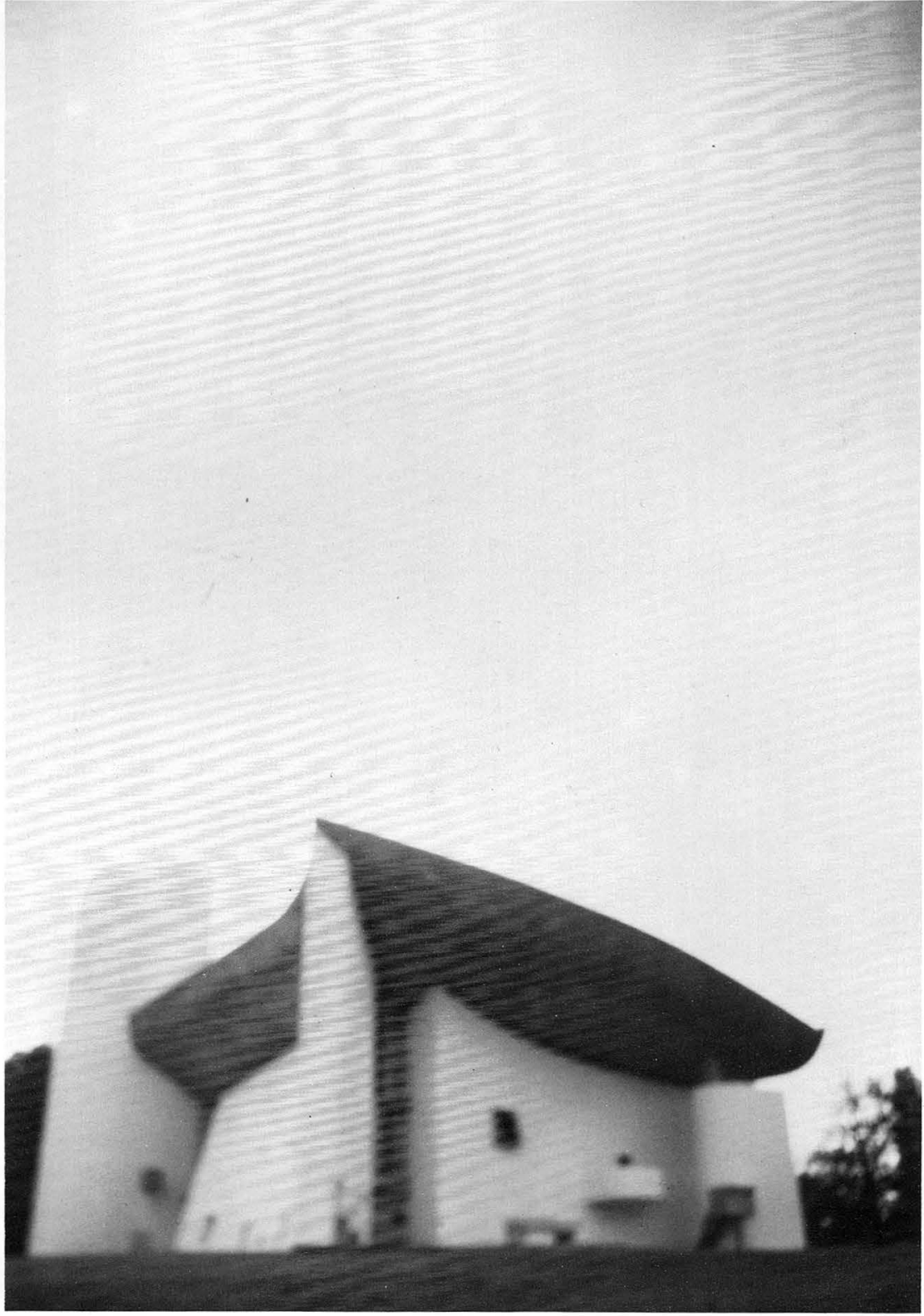

"The Source" 
pleteness of the design reality contains a resemblance to the completeness of our imaginations. Frances Yates puts it this way: "If a building has an immaterial existence in the mind of the architect before it is built, it has also many immaterial existences in the memories of those who have seen it ...."

\section{III.}

One of the differences between our age and any other is that the potential sources for memory are more plentiful than ever. For purposes of this discussion, the modern sources of memory can be categorized into two groups. First are memories generated by real experience (experiences personally encountered) Memories from real experiences are the type of memories human beings have always had. These sorts of memories are rich in many aspects, primarily because they engage all of our senses. They also occur at full scale and in real time.

The second category of memories are those generated by mediated experience (experiences mediated through narrative, technology, print, etc.). Human beings developed many ways to provide symbolic representations of images, events, and ideas. In general these can be divided into verbal sources (oral and written traditions) and pictorial sources (drawing, painting, photography, film, video, and television). Of course, film, video, and television give us both pictorial and verbal experiences. It can be argued that a growing percentage of our memories come from mediated sources, especially television. Our entire culture is comfortable with this mode of experience. It has its advantages and its drawbacks.

Certainly media is positive in the sense that it exposes us to a much wider world of information and possibility than we could ever experience in person. Withou disputing the possible value of media for its informational and entertainment role, what is of concern here is that more and more of our "experiences" come from mediated sources that allow us physical and often emotional detachment from the source ("Don't cry, it's only a movie."). We perhaps are fooled into believing that we understand things that have been re presented to us in mediated form. What we really understand or know is the particular slice of the thing framed in a particular way. It is,-at best, a limited ex perience. In terms of its impact on the qualities of memory, the invention of mass media is, clearly, a poor trade-of against real experience.

A curious thing about memory is that it is usually inaccurate. Things that are small or insignificant can gain significance because we paid attention to them. The emotional tenor of the situation in which we experience an event certainly sways our recollection of it. Certainly memory is vulnerable to subjectivity and the passage of time. We do not understand what causes us to register some things in our memories and not others. However we seem to accept these faults and to rely upon our memories.
The point of all this discussion about real and mediated experiences is that we need to be aware of the differences in the quality and completeness of the memories they give us to draw upon in our lives. Memory generated from personal experience has three dimensionality, sensory completeness, kinesthetic understanding, emotional subjectivity, and fallibility. Memory generated from mediated sources is two-dimensional, has visual and sometimes auditory impact, registers some emotional subjectivity, but allows for confirmation by its nature of repeatability in absolute terms.

Perhaps one of the troubling issues in a world dominated by mediated sources of memory is the issue of control over memory formation. Each potential source of memory has an implicit degree of control with it. Questions of control are: who chooses what information is taken into memory; is there an opportunity to review the information or to question it or to view it from another angle; is there a range of interpretations possible; is there the potential for falsehood in the information; is there the potential for ascertaining truth; is the information sought or imposed; and on and on?

Certainly, because of the sheer amount of information available, we have a tendency to rely on other people to preselect for us what is worthy of our attention. A great deal of concern has been expressed in recent years about the role that broadcast news plays in determining what news items and world events are considered "newsworthy." In architecture, preselection is done first by teachers - who in turn are drawing from sources preselected by historians, critics, and journal editors, who in turn were educated by teachers ... and on it goes.

\section{IV.}

William James defines memory as follows: "It (memory) is the knowledge of an event or fact, of which meantime we have not been thinking, with the additional consciousness that we have thought or experienced it before."2 Memory, then, is a noun - the thing, the knowledge itself, in storage in the electricity of our brain. When we actually use our memories we use the verb "to remember." Remembering implies a conscious effort of recall. We know abstractly that some piece of information is in our memory. We must retrieve it in order to use it. Certainly there are times when memories come to our conscious minds unbidden, or when a memory refuses to reveal itself when we know it is there. We have all experienced difficulty with conscious recall of names or even the details of an event.

When the idea of remembering based upon real and mediated memory is translated to architecture, new problems arise. Architecture is a four-dimensional multi-sensory experience. When we remember a profound architectonic experience, we remember much more than particular visual components. All of our senses have been affected. We have en- 
gaged the architecture as a full scale temporal experience. We remember the phenomenon of the textures; the temperature and humidity; the changes in perspective and scale; the acoustic quality of spaces; the smell of materials, dampness, vegetation; and the changing quality of light. As architects or people interested in architecture, such experiences are processed into memory carefully to be drawn upon at a later date. This is the strength of the real experience of architecture: the understanding of buildings as sensuous and material things. This aspect of real experience was certainly appreciated early in the development of architecture as a profession. The Grand Tour of Europe was essential to any young man (sic) who wanted to pursue architecture with any seriousness. He had to see and to draw, in person, the antiquities. The act of drawing served to reinforce the commitment of the building to memory.

When we learn about a building through sources other than direct experience, we have only an idea of its nature. We may have a series of images (photographs or drawings) and diagrams (plans, sections, elevations, axonometrics, etc.) that convey to us a kind of information about the building. Film and video allow for a temporal unfolding of the building through the eye of the camera, and can also convey certain acoustic characters of space. These visual images can also be enhanced by verbal descriptions of the missing components of the experience through the sensibility of someone else. framed for us by someone else. Not only are they mediated by technology, but they are mediated by another person's mind, by their perception of what is interesting or worthy of notice. The frame used to capture an image also excludes the rest of the world. Furthermore, the instrument used to capture the mediated image can distort the reality of the building, as with the use of a wide-angle lens - a favorite for the photography of interiors.

Architecture is both a sensual and an intellectual endeavor. The focus in much of contemporary architectural press and architectural education is upon intellectual understanding mediated through writings and photographs. The intellectual issues can be described, analyzed, and even judged. We can gain a great deal of intellectual understanding about a place through mediated images. These images may, therefore, seem adequate to our purposes of understanding buildings.

Some sensual (visual) content can be communicated through photographs that focus on the poetic qualities of a place. Drawings and verbal description can flesh out our understanding. This is especially true if we have a strong backlog of real experiences to draw upon. Experience is translated into architecture through memory. One of the main differences between beginning architects and mature architects using mediated images as sources is that the mature architects generally have enough experience with the real world and a variety of real buildings to flesh out the mediated images. The thick line representing a wall on a floor plan is read as massive material. The scale of the room drawn at $1 / 4$ scale is intuitively known.

It is important even for a mature architect not to think that a building is really known and understood when it has only been experienced through mediating devices. This becomes particularly important when designing for our ex perience is translated into architecture from our imaginations and our memories. As Yates explains about immateriality, if we work only from mediated memories we can probably expect buildings that have the two dimensional qualities of such memories. $^{3}$

It is precisely such two-dimensionality that has become the focus for so much ar chitectural criticism (from professional critics to "ordinary" people). We know that there is more to architecture. We have all felt it sometime in our lives. We should be ashamed as students and practitioners to imagine or produce buildings that are flat, lifeless, and devoid of real experiences. Most of us have come to love the architecture that addresses our senses and acknowledges our bodies.

\section{V.}

The solution to the memory dilemma is not singular, nor is it straightforward. The first thing this discussion seems to imply is that all of us who make architecture should be out experiencing it firsthand as much as possible. While the issue of what architecture we experience should be left for another time, let it suffice to say that there are lessons for us everywhere and in almost every sort of building type. The Grand Tour, while wonderful, is not necessary. Nor do the antiquities contain all there is to understand about architectural experience. Nor are the best lessons always contained in big, famous buildings designed by architects whose names we all recognize. Yes, Dorothy, it may have been in your own back yard all along.

The second thing is to be far more rigorous in our engagement of mediated experiences of buildings. We need to take time with the images and attempt to make the building come into three dimensional and experiential materiality in our minds. This is not to say that such attempts will always result in an accurate mental reconstruction of the project, but it is probably far preferable to a mindless absorption of single, disconnnected images.

\section{VI.}

What of the poor student hung out to dry in front of the critics at the end of the semester? The student was clearly familiar with the image, in photograph or slide, of the famous wall at Notre Dame du Haut. The extent of his knowledge of the building was likely a survey course of 20 th century architecture. Since the building is so obviously admired by so many people, must be good. And since the building is good (if a bit disturbing to the newly initiated), then one part of it must be good. And since it was shown as a 
facade, maybe described as important, then the image of the facade sticks with the student as a valid and accepted alternative to an "ordinary" facade. And, since students are almost always looking for something "different," the image of the Ronchamps' facade inevitably shows up (usually in the student's drawings the night before the project review). The student is a victim of perhaps the most common architectural memory error. He assumed that the architectural merit of the Ronchamps wall lay (only) in its image. $\mathrm{He}$, of course, was mistaken.

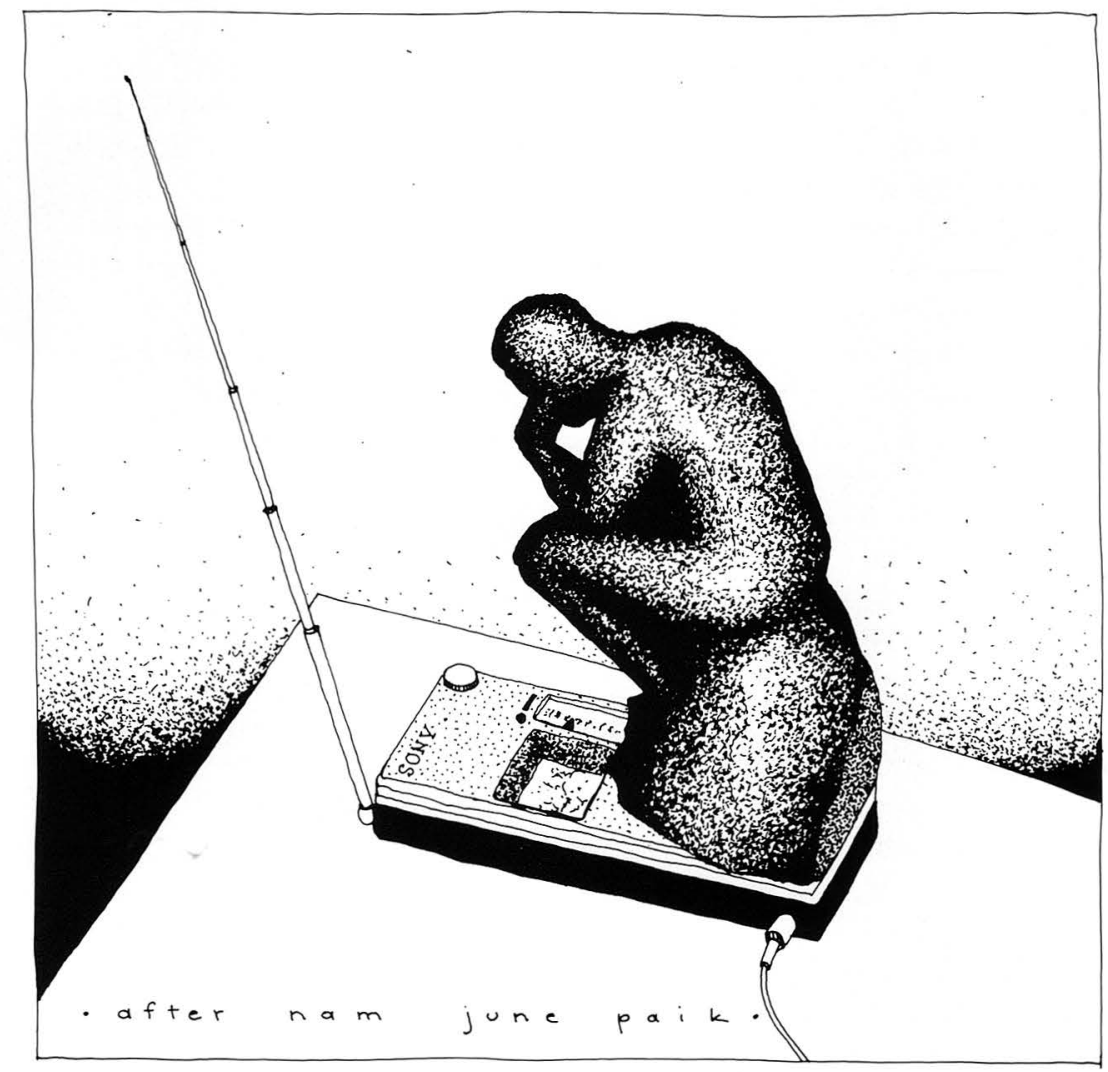

\section{FOOTNOTES:}

1. Yates, Frances "Architecture and the Art of Memory," a paper delivered at the Architectural Association, London, in 1980 (as quoted by Quantrill, pg. xxil

2. Yates, pg. 32

3. Socrates, Phaedrus (as quoted by Yates, pg. 38) REFERENCES

Bergson, Henri Matter and Memory, George Allen \& Unwin, LTD, London, 1962

Durant, Will The Story of Pbilosophy, Simon and Schuster, New York, 1926

Gardner, Howard Art, Mind \& Brain, Basic Books, Inc., New York, 1982

Quantrill, Malcolm The Environmental Memory, Schocken Books, New York, 1987

Smith, Brian Memory, George Allen \& Unwin, LTD, London, 1966

Yates, Frances A. The Art of Memory, U. of Chicago Press, 1966 